\title{
Prevalence of Methicillin-Resistant Staphylococcus aureus in Raw Hamburgers and Ready-to-Eat Sandwiches Commercialized in Supermarkets and Fast Food Outlets in Brazil
}

\author{
Claudia Patrícia Álvarez Contreras, Lis Nery Nunes da Silva, \\ Dilza Caroline Gomes Ferreira, Jeane dos Santos Ferreira, \\ Rogeria Comastri de Castro Almeida* \\ Department of Food Science, Nutrition School, Federal University of Bahia, Salvador, Brazil \\ Email: rogeriac@ufba.br
}

Received 6 July 2015; accepted 27 October 2015; published 30 October 2015

Copyright (C) 2015 by authors and Scientific Research Publishing Inc.

This work is licensed under the Creative Commons Attribution International License (CC BY). http://creativecommons.org/licenses/by/4.0/

(c) (i) Open Access

\begin{abstract}
Although well known, Staphylococcus aureus is a bacterium that remains widely studied because of its high pathogenic potential and its ability to develop resistance to antibiotics routinely used in clinical practice. The present study investigated the occurrence of methicillin-resistant Staphylococcus aureus (MRSA) in hamburgers and sandwiches sold in supermarkets and fast food outlets in Salvador, BA, Brazil. Fifty samples of frozen raw hamburgers (25: beef and 25: chicken) and 50 samples of ready-to-eat sandwiches (25: beef and 25: chicken) were collected and investigated for the presence of MRSA. MRSA was present in 32\% of the hamburgers and $8 \%$ of the sandwiches. The frequency of MRSA was higher in the samples containing chicken meat. However, the statistical analysis showed no association between MRSA presence and the type of meat investigated $(P>$ 0.05). The high prevalence of MRSA in hamburgers and the presence of the microorganism in ready-to-eat sandwiches are worrying and indicate the need for better control during food preparation to prevent the spread of bacteria.
\end{abstract}

\section{Keywords}

Methicillin-Resistant Staphylococcus aureus, Hamburgers, Sandwiches, Food Safety

\footnotetext{
${ }^{*}$ Corresponding author.

How to cite this paper: Contreras, C.P.Á., et al. (2015) Prevalence of Methicillin-Resistant Staphylococcus aureus in Raw Hamburgers and Ready-to-Eat Sandwiches Commercialized in Supermarkets and Fast Food Outlets in Brazil. Food and Nutrition Sciences, 6, 1324-1331. http://dx.doi.org/10.4236/fns.2015.614138
} 


\section{Introduction}

With the reduced time available for food preparation and/or consumption, in recent years, there have been changes in individuals' eating habits, motivated especially by urbanization processes and the professionalization of women, substantially favoring the consumption of processed products and food prepared away from home. Thus, the search for ready-to-eat meals produced on a large scale and with reduced cost has culminated in an increased number of fast-foods outlets and individuals eating in cafeterias and trailers [1]-[3].

Staphylococcus aureus is considered the third-most important cause of food-borne disease in the world [4] and has two aggravating characteristics, toxin production and antimicrobial resistance. This pathogen is considered an excellent indicator of thermal processing inefficiency, inadequate hygienic conditions during food production/preparation, or inadequate cooling after food preparation [5].

Regarding antimicrobial resistance, S. aureus is one of the most microorganisms implicated in cases of nosocomial infection worldwide. The methicillin-resistant Staphylococcus aureus (MRSA) was considered a nearly exclusively responsible pathogen in hospital-acquired infections between 1930 and 1980; however, at the end of 1990, MRSA infections among healthy individuals began to emerge [6] [7].

$S$. aureus resistance to antibiotics is due to the production of a penicillinase, an enzyme that inactivates the beta-lactâmico ring of the penicillin molecule, making the antibiotic ineffective against $S$. aureus. Methicillin resistance presented by $S$. aureus is mediated by the presence of the mecA gene, which encodes the 2a protein (PBP2a) found in the cell wall of the microorganism [7]-[10].

In particular, strains of MRSA harboring genes encoding the Panton-Valentine leukocidin (PVL) toxin are of concern from a public health perspective because they are usually capable of causing severe skin and soft tissue infections and occasionally necrotizing pneumonia, which is associated with high mortality [11].

This study aimed to investigate the occurrence of methicillin-resistant S. aureus (MRSA) in sandwiches and hamburgers marketed in Salvador, BA, and evaluate the association between MRSA isolates and investigated meat.

\section{Material and Methods}

\subsection{Detection of MRSA}

\section{Sampling and Laboratory Procedures}

Fifty samples of frozen raw hamburgers (25 beef and 25 chicken) and 50 samples of ready-to-eat sandwiches (25 beef and 25 chicken) were collected from supermarkets and fast food outlets, respectively, in the city of Salvador, Bahia, in northeastern Brazil, from September 2013 through December 2013.

To detect MRSA, approximately $500 \mathrm{~g}$ of frozen hamburger and $200 \mathrm{~g}$ of ready-to-eat sandwiches were aseptically collected in supermarkets and fast food outlets, respectively, and transported to the laboratory for analysis. Prior to analysis, hamburger samples were defrosted in the original package under refrigeration for 24 hours. For sandwiches, the meat (beef or chicken) and bread portions were separated, and the bread was discarded. Approximately $25 \mathrm{~g}$ of each food was added to $225 \mathrm{ml}$ of Tryptic Soy Broth (TSB, Difco, Detroit, MI, USA) supplemented with 6.5\% NaCl and homogenized in a Stomacher (240 bpm; ITR model 1204, series 126, Esteio, RS, Brazil) for 2 min in a class II biosafety cabinet (Labconco Corporation, Labconco Purifier Class IIb, Total Exhaust, model 36210-04, certified ISO 9002, Kansas City, MO, USA). This homogenate was then incubated at $37^{\circ} \mathrm{C}$ for 16 - 20 h. Next, a 1-ml aliquot was added to $9 \mathrm{ml}$ of Phenol Red Mannitol Broth (PHMB, HiMedia, São Paulo, SP, Brazil) containing ceftizoxime $(5 \mu \mathrm{g} / \mathrm{ml})$ and aztreonam $(75 \mu \mathrm{g} / \mathrm{ml})$ (Sigma-Aldrich Brazil Ltda, São Paulo, SP, Brazil). From the culture obtained in PHMB, the surface of the hypertonic mannitol agar (HMA, HiMedia, São Paulo, SP, Brazil) was inoculated with a sterile loop. The plates were incubated for $24 \mathrm{~h}$ at $37^{\circ} \mathrm{C}$ and examined for typical colonies, Gram, catalase and coagulase. For confirmation, a maximum of five typical colonies per plate were purified on Tryptic Soy Agar (TSA, Difco, Detroit, MI, USA) and subjected to antibiotic susceptibility testing using the disc diffusion method [12].

\subsection{In Vitro Susceptibility to Antibiotics Testing}

Cells were grown overnight at $35^{\circ} \mathrm{C}$ in TSB, suspended in saline solution and adjusted to 0.5 on the McFarland scale (c.a. $10^{8} \mathrm{CFU}$ ). The cell suspensions were inoculated with a swab in Mueller-Hinton agar (MHA, HiMedia, São Paulo, SP, Brazil). Bacterial growth was recorded after 18 - 24 h of incubation at $35^{\circ}$ C. One Staphylococcus 
aureus (ATCC 25923) negative control and one methicillin-resistant Staphylococcus aureus (ATCC 33591) positive control were used for each set of analyzed samples. Antibiotic susceptibility testing was performed using Kirby-Bauer disk diffusion on Mueller-Hinton medium according to the recommendations of the Clinical Laboratory Standards Institute [13]. The isolates were tested against a panel of seven antimicrobial agents: penicillin G (PEN) (10 UI), erythromycin (ERI) $(15 \mu \mathrm{g})$, tetracycline (TET) $(30 \mu \mathrm{g})$, oxacillin (OXA) $(1 \mu \mathrm{g})$, cefoxitin (CEF) $(30 \mu \mathrm{g})$, vancomycin (VCM) $(30 \mu \mathrm{g})$ and ciprofloxacin (CIP) $(5 \mu \mathrm{g})$. The antibiotic disks were purchased from Interlab (Laborclin, Interlab, São Paulo, SP, Brazil).

\subsection{Statistical Analysis}

The Pearson's chi-square $\left(\mathrm{X}^{2}\right)$ (SPSS 17.0 for Windows) was used to determine significant differences $(P<0.05)$ in MRSA contamination between the investigated meats.

\section{Results and Discussion}

A total of 34 hamburger samples were positive for coagulase-positive Staphylococci, 16 (64\%) hamburgers made with beef and 18 (72\%) made with chicken meat. For the sandwiches, 7 samples were contaminated, 5 (20\%) sandwiches made with beef and 2 (8\%) made with chicken meat (Table 1).

The MRSA prevalence results in the samples are summarized in Table 2. MRSA strains were isolated from $32 \%$ of the hamburger samples and $8 \%$ of the sandwiches.

Although the hamburger samples made with chicken meat had the highest prevalence of MRSA, no association between MRSA contamination and type of meat investigated was observed $(P>0.05)$.

The resistant/susceptibility profile of the coagulase-positive Staphylococci isolated from the samples is demonstrated in Table 3 and Table 4. In chicken meat samples from sandwiches, resistance equal or higher than $50 \%$ was observed for penicillin G (66.7\%), erythromycin (50.0\%) and oxacillin (66.7\%) (Table 3). For isolates from hamburgers made with beef or chicken meat, resistance was always lower than $50 \%$ (Table 4).

The present results indicated a high prevalence of MRSA in raw hamburger compared with Kitai et al. [14], Van Loo et al. [15], De Boer et al. [12], Weese [16], Fessler et al. [17], Hanson et al. [18], and Agerso et al. [19].

In Japan, only two strains of $S$. aureus, both isolated from chicken thigh muscle parts, have been identified as MRSA, suggesting that food handlers have accidentally transmitted the pathogen [14]. Improper handling is currently the primary source of contamination of foodstuffs, and proper hand hygiene, with warm water and soap and antiseptic, would prevent such contamination [20].

Here, the presence of MRSA in ready-to-eat sandwiches indicates that the beef and chicken meat were

Table 1. Frequency of isolation of coagulase-positive Staphylococci in hamburger and sandwich samples.

\begin{tabular}{ccccc}
\hline Meat/food & \multicolumn{3}{c}{ Hamburgers } & Sandwiches \\
\cline { 2 - 5 } & $\begin{array}{c}\text { Samples } \\
\text { (n) }\end{array}$ & $\begin{array}{c}\text { Coagulase-positive Staphylococci } \\
\text { positive samples (\%) }\end{array}$ & $\begin{array}{c}\text { Samples } \\
\text { (n) }\end{array}$ & $\begin{array}{c}\text { Coagulase-positive Staphylococci } \\
\text { positive samples (\%) }\end{array}$ \\
\hline Beef & 25 & $16(64.0)$ & 25 & $5(20.0)$ \\
Chicken & 25 & $18(72.0)$ & 25 & $2(8.0)$ \\
Total & $\mathbf{5 0}$ & $\mathbf{3 4}(\mathbf{6 8 . 0 )}$ & $\mathbf{5 0}$ & $\mathbf{7 ( 1 4 . 0 )}$ \\
\hline
\end{tabular}

Table 2. Frequency of MRSA isolation in hamburger and sandwich samples.

\begin{tabular}{ccccc}
\hline & \multicolumn{2}{c}{ Hamburgers } & \multicolumn{2}{c}{ Sandwiches } \\
\cline { 2 - 5 } Meat/food & $\begin{array}{c}\text { Samples } \\
\text { (n) }\end{array}$ & $\begin{array}{c}\text { MRSA } \\
\text { positive samples (\%) }\end{array}$ & $\begin{array}{c}\text { Samples } \\
\text { (n) }\end{array}$ & $\begin{array}{c}\text { MRSA } \\
\text { positive samples (\%) }\end{array}$ \\
Beef & 25 & $4(16.0)$ & 25 & $2(8.0)$ \\
Chicken & 25 & $12(48.0)$ & 25 & $2(8.0)$ \\
Total & $\mathbf{5 0}$ & $\mathbf{1 6 ( 3 2 . 0 )}$ & $\mathbf{5 0}$ & $\mathbf{4 ( 8 . 0 )}$ \\
\hline
\end{tabular}


Table 3. Antimicrobial activity of antibiotics against positive-coagulase Staphylococci isolated from sandwiches.

\begin{tabular}{|c|c|c|c|c|c|}
\hline \multirow[t]{2}{*}{ Profile } & \multicolumn{4}{|c|}{ Sandwiches } & \multirow[b]{3}{*}{$P$-value } \\
\hline & \multicolumn{2}{|c|}{ Chicken } & \multicolumn{2}{|c|}{ Beef } & \\
\hline Penicillin G & $\mathrm{N}$ & $\%$ & $\mathrm{~N}$ & $\%$ & \\
\hline Resistant & 2 & 66.7 & 3 & 23.1 & 0.265 \\
\hline Intermediary & 0 & 0.0 & 5 & 38.5 & \\
\hline Susceptible & 1 & 33.3 & 5 & 38.5 & \\
\hline Total & 3 & 100.0 & 13 & 100.0 & \\
\hline \multicolumn{6}{|l|}{ Erythromycin } \\
\hline Resistant & 2 & 50.0 & 2 & 15.4 & 0.154 \\
\hline Intermediary & 0 & 0.0 & 0 & 0.0 & \\
\hline Susceptible & 2 & 50.0 & 11 & 84.6 & \\
\hline Total & 4 & 100.0 & 13 & 100.0 & \\
\hline \multicolumn{6}{|l|}{ Tetracycline } \\
\hline Resistant & 0 & 0.0 & 1 & 6.7 & 0.182 \\
\hline Intermediary & 1 & 20.0 & 0 & 0.0 & \\
\hline Susceptible & 4 & 80.0 & 14 & 93.3 & \\
\hline Total & 5 & 100.0 & 15 & 100.0 & \\
\hline \multicolumn{6}{|l|}{ Oxacillin } \\
\hline Resistant & 2 & 66.7 & 3 & 21.0 & 0.241 \\
\hline Intermediary & 0 & 0.0 & 5 & 35.7 & \\
\hline Susceptible & 1 & 33.3 & 6 & 42.9 & \\
\hline Total & 3 & 100.0 & 14 & 100.0 & \\
\hline \multicolumn{6}{|l|}{ Cefoxitin } \\
\hline Resistant & 0 & 0.0 & 0 & 0.0 & - \\
\hline Intermediary & 0 & 0.0 & 0 & 0.0 & \\
\hline Susceptible & 5 & 100.0 & 15 & 100.0 & \\
\hline Total & 5 & 100.0 & 15 & 100.0 & \\
\hline \multicolumn{6}{|l|}{ Vancomycin } \\
\hline Resistant & 0 & 0.0 & 0 & 0.0 & 0.054 \\
\hline Intermediary & 1 & 25.0 & 0 & 0.0 & \\
\hline Susceptible & 3 & 75.0 & 14 & 100.0 & \\
\hline Total & 4 & 100.0 & 14 & 100.0 & \\
\hline \multicolumn{6}{|l|}{ Ciprofloxacin } \\
\hline Resistant & 0 & 0.0 & 0 & 0.0 & - \\
\hline Intermediary & 0 & 0.0 & 0 & 0.0 & \\
\hline Susceptible & 4 & 100.0 & 15 & 100.0 & \\
\hline Total & 4 & 100.0 & 15 & 100.0 & \\
\hline
\end{tabular}


Table 4. Antimicrobial activity of antibiotics against coagulase-positive Staphylococci isolated from hamburgers.

\begin{tabular}{|c|c|c|c|c|c|}
\hline \multicolumn{6}{|c|}{ Hamburgers } \\
\hline \multirow{2}{*}{ Penicillin G } & \multicolumn{2}{|c|}{ Chicken } & \multicolumn{2}{|c|}{ Beef } & \multirow[b]{2}{*}{$P$-value } \\
\hline & $\mathrm{N}$ & $\%$ & $\mathrm{~N}$ & $\%$ & \\
\hline Resistant & 19 & 43.2 & 10 & 33.3 & 0.391 \\
\hline Intermediary & 15 & 34.1 & 15 & 50.0 & \\
\hline Susceptible & 10 & 22.7 & 5 & 16.7 & \\
\hline Total & 44 & 100.0 & 30 & 100.0 & \\
\hline \multicolumn{6}{|l|}{ Erythromycin } \\
\hline Resistant & 11 & 35.5 & 6 & 21.4 & 0.234 \\
\hline Intermediary & 0 & 0.0 & 0 & 0.0 & \\
\hline Susceptible & 20 & 64.5 & 22 & 78.6 & \\
\hline Total & 31 & 100.0 & 28 & 100.0 & \\
\hline \multicolumn{6}{|l|}{ Tetracycline } \\
\hline Resistant & 12 & 25.0 & 7 & 21.9 & 0.703 \\
\hline Intermediary & 7 & 14.6 & 3 & 9.4 & \\
\hline Susceptible & 29 & 60.4 & 22 & 68.8 & \\
\hline Total & 48 & 100.0 & 32 & 100.0 & \\
\hline \multicolumn{6}{|l|}{ Oxacillin } \\
\hline Resistant & 11 & 39.3 & 9 & 31.0 & 0.480 \\
\hline Intermediary & 2 & 7.1 & 5 & 17.2 & \\
\hline Susceptible & 15 & 53.6 & 15 & 51.7 & \\
\hline Total & 28 & 100.0 & 29 & 100.0 & \\
\hline \multicolumn{6}{|l|}{ Cefoxitin } \\
\hline Resistant & 1 & 2.3 & 0 & 0.0 & 0.455 \\
\hline Intermediary & 1 & 2.3 & 0 & 0.0 & \\
\hline Susceptible & 41 & 95.3 & 33 & 100.0 & \\
\hline Total & 43 & 100.0 & 33 & 100.0 & \\
\hline \multicolumn{6}{|l|}{ Vancomycin } \\
\hline Resistant & 2 & 5.0 & 0 & 0.0 & 0.200 \\
\hline Intermediary & 0 & 0.0 & 0 & 0.0 & \\
\hline Susceptible & 38 & 95.0 & 32 & 100.0 & \\
\hline Total & 40 & 100.0 & 32 & 100.0 & \\
\hline \multicolumn{6}{|l|}{ Ciprofloxacin } \\
\hline Resistant & 0 & 0.0 & 0 & 0.0 & 0.228 \\
\hline Intermediary & 2 & 4.2 & 0 & 0.0 & \\
\hline Susceptible & 46 & 95.8 & 34 & 100.0 & \\
\hline Total & 48 & 100.0 & 34 & 100.0 & \\
\hline
\end{tabular}


insufficiently cooked or that cross-contamination occurred after cooking in sandwich preparation by an asymptomatic food handler or utensils.

In Brazil, Costa [21] reported that some preparations of meats ready for consumption were contaminated with MRSA. The author considered the occurrence of contamination after the preparation of the meat dishes by asymptomatic carriers or contaminated utensils used in the distribution of meals, once the thermal processing was sufficient to eliminate the microorganism.

According to the results of the present study, $66.7 \%$ of the coagulase-positive Staphylococci isolated from samples of chicken sandwiches were resistant to penicillin, a drug used in human and veterinary medicine. For beef sandwiches, this resistance was observed in only $23.1 \%$ of the isolates.

In Brazil, the resistance of the S. aureus to penicillin varies from $20 \%$ to $100 \%$, whereas the percentage of resistance to other antimicrobials is lower [22]. In several countries, however, large-scale studies have shown that resistance of the microorganism to penicillin is approximately $60 \%$, and studies from 11 different countries have demonstrated that the prevalence of samples resistant to various antibacterials routinely used to treat mastitis was generally low [23].

Susceptibility to vancomycin, the drug of choice for MRSA treatment in humans, was observed in all isolates from samples of beef sandwiches and beef hamburgers, whereas $75 \%$ of the isolates from chicken sandwiches were susceptible (Table 3). These results indicate that selecting vancomycin for MRSA infection treatment is suitable.

Cefoxitin was recently shown to be a marker of resistance to MRSA. However, the results demonstrated that $100 \%$ of the isolates of sandwiches samples were susceptible to this marker (Table 3). For hamburger samples, similar results were found (Table 4).

Fessler et al. [17] demonstrated that all MRSA isolates were resistant to oxacillin, and 62.5\% exhibited multidrug resistance. Hanson et al. [18] showed that MRSA isolated from samples of pork, beef, chicken, and turkey were resistant to oxacillin and were multidrugresistant. Van Loo et al. [15] found similar results to those of Hanson et al. [18]; i.e., samples of pork and beef were contaminated with MRSA, and all isolates were resistant to oxacillin and cefoxitin. Recently, Lin et al. [24] found that S. aureus ST398 isolated from retail foods were most frequently resistant to penicillin (100\%), followed by trimethoprim, erythromycin, ampicillin (each $86.7 \%$ ), clindamycin (80.0\%), and tetracycline (26.7\%). All ST398 isolates were susceptible to amikacin, chloramphenicol, cefoxitin, gentamicin, oxacillin, and vancomycin.

According to Hososaka et al. [25], some clinical isolates of S. aureusare mec A-positive and susceptible to oxacillin. The presence of this gene was verified in strains of $S$. aureus identified as methicillin-susceptible (MSSA) that were isolated from hamburgers [26].

Due to the growing problem of microbial resistance, the outlook for the use of antimicrobial drugs is uncertain. Consequently, research intending to increase antibacterial activity and characterize the interaction mechanism with antibiotics is needed.

\section{Conclusion}

The high prevalence of MRSA among the tested foods, primarily in raw hamburger made from chicken meat, and the presence of the microorganism in prepared ready-to-eat sandwiches highlights the necessity of enforcing hygienic practices within the food industry and fast food outlets. Better knowledge of the transmission routes of MRSA in the food chain, "from the farm to the fork", is necessary to provide tools for preventing the spread of MRSA, clarify the possible health hazards for consumers related to the presence of MRSA in foods, and determine adequate measures for MRSA control.

\section{Acknowledgements}

The authors thank the Coordenação de Aperfeiçoamento de Pessoal de Nivel Superior (CAPES) of the government of Brazil for scholarship support.

\section{References}

[1] Fattori, F.F.A., Souza, L.C., Braoios, A., Ramos, A.P.D., Tashima, N.T., Neves, T.R.M. and Barbosa, H.R.L. (2005) Sanitary Aspects of Snacks Sold in Trailers in Presidente Prudente City, Brazil. Higiene Alimentar, 19, 54-62. 
[2] Levré, E., Valentini, P. and Chiaverini, F. (2000) Presenza di E. coli O157 verocitotossigeni inhamburger di carne bovina. Annali di Igiene, 12, 131-137.

[3] Tavares, T.M. and Serafini, A.B. (2003) Microbiological Evaluation of Ground Beef Hamburgers Commercialized in Snack Bars in Goiânia City, Brazil. Revista de Patologia Tropical, 32, 45-52.

[4] Normanno, G., Corrente, M., La Salandra, G., Dambrosio, A., Quaglia, N.C., Parisi, A., Greco, G., Bellacicco, A.L., Virgilio, S. and Celano, G.V. (2007) Methicillin-Resistant Staphylococcus aureus (MRSA) in Foods of Animal Origin Product in Italy. International Journal of Food Microbiology, 117, 219-222. http://dx.doi.org/10.1016/j.ijfoodmicro.2007.04.006

[5] Jay, J.M. (2000) Modern Food Microbiology. 6th Edition, Aspen Publishers, Inc., Gaithersburg. http://dx.doi.org/10.1007/978-1-4615-4427-2

[6] Calfee, D.P. (2011) The Epidemiology, Treatment, and Prevention of Transmission of Methicillin-Resistant Staphylococcus aureus. The Art and Science of Infusion Nursing, 34, 359-364. http://dx.doi.org/10.1097/NAN.0b013e31823061d6

[7] Vaz, M.J.S.A.M. (1995) Characterization of Bacterial Resistance in Staphylococcus aureus. Thesis, Porto University, Porto.

[8] Chambers, H.F. (1997) Methicillin-Resistance in Staphylococci Molecular and Biochemical Basis and Clinical Implications. Clinical Microbiology Reviews, 10, 781-791.

[9] De Leo, F.R. and Chambers, H.F. (2009). Reemergence of Antibiotic-Resistant Staphylococcus aureus in the Genomics Era. The Journal of Clinical Investigations, 119, 2464-2474. http://dx.doi.org/10.1172/JCI38226

[10] Sturmer, F.C.R. (2008) Partial Characterization of Cor Element in Methicillin-Resistant Staphylococcus aureus Isolates from Southern Brazil. Dissertation, Federal University of Porto Alegre, Porto Alegre.

[11] Kraushaar, B. and Fetsch, A. (2014) First Description of PVL-Positive Methicillin-Resistant Staphylococcus aureus (MRSA) in Wild Boar Meat. International Journal of Food Microbiology, 186, 68-73. http://dx.doi.org/10.1016/j.ijfoodmicro.2014.06.018

[12] De Boer, E., Zwartkruis-Nahuis, J.T.M., Wit, B., Huijsdens, X.W., de Neeling, A.J., Bosch, T., van Oosterom, R.A.A., Vila, A. and Heuvelink, A.E. (2009) Prevalence of Methicillin-Resistant Staphylococcus aureus in Meat. International Journal of Food Microbiology, 134, 52-56. http://dx.doi.org/10.1016/j.ijfoodmicro.2008.12.007

[13] CLSI (2011) Performance Standards for Antimicrobial Susceptibility Testing. Twenty-First Informational Supplement 31, M100-S21, Clinical and Laboratory Standards Institute, Wayne.

[14] Kitai, S., Shimizu, A., Kawano, J., Sato, E., Nakano, C., Uji, T. and Kitagawa, H. (2005) Characterization of Methicillin-Resistant Staphylococcus aureus Isolated from Retail Raw Chicken Meat in Japan. Journal of Veterinary Medical Science, 67, 107-110.

[15] Van Loo, I., Huijsdens, X., Tiemersma, E., De Neeling, A. and Van de Sande-Bruinsma, N. (2007) Emergence of Methicillin-Resistant Staphylococcus aureus of Animal Origin in Humans. Emerging Infectious Diseases, 13, 1834-1839. http://dx.doi.org/10.3201/eid1312.070384

[16] Weese, J.S. (2010) Methicillin-Resistant Staphylococcus aureus in Animals. ILARS Journal, 51, 338-342. http://dx.doi.org/10.1093/ilar.51.3.233

[17] Fessler, A.T., Kadlec, K., Hassel, M., Hauschild, T., Eidam, C. and Ehricht, R. (2011) Characterization of Methicillin-Resistant Staphylococcus aureus Isolates from Food and Food Products of Poultry Origin in Germany. Applied and Environmental Microbiology, 77, 7151-7157. http://dx.doi.org/10.1128/AEM.00561-11

[18] Hanson, B.M., Dressler, A.E., Harper, A.L., Scheibel, R.P., Wardyn, S.E. and Roberts, L.K. (2011) Prevalence of Staphylococcus aureus and Methicillin-Resistant Staphylococcus aureus (MRSA) on Retail Meat in Iowa. Journal of Infection and Public Health, 4, 169-174. http://dx.doi.org/10.1016/j.jiph.2011.06.001

[19] Agerso, Y., Hasman, H., Cavaco, L.M., Pedersen, K. and Aarestrup, F.M. (2012) Study of Methicillin Resistant Staphylococcus aureus (MRSA) in Danish Pigs at Slaughter and in Imported Retail Meat Reveals a Novel MRSA Type in Slaughter Pigs. Veterinary Microbiology, 157, 246-250. http://dx.doi.org/10.1016/j.vetmic.2011.12.023

[20] Soares, L.S., Almeida, R.C.C., Cerqueira, E.S., Carvalho, J.S. and Nunes, I.L. (2012) Knowledge, Attitudes, and Practices in Food Safety and the Presence of Coagulase-Positive Staphylococci on Hands of Food Handlers in the Schools of Camaçari, Brazil. Food Control, 27, 206-213. http://dx.doi.org/10.1016/j.foodcont.2012.03.016

[21] Costa, W.L.R., Ferreira, J.S., Carvalho, J.S., Cerqueira, E.S., Oliveira, L.C. and Almeida, R.C.C. (2015) MethicillinResistant Staphylococcus aureus in Raw Meats and Prepared Foods in Public Hospitals in Salvador, Bahia, Brazil. Journal of Food Science, 80, M147-M150. http://dx.doi.org/10.1111/1750-3841.12723

[22] Andreotti, R. and Nicodemo, M.L.F. (2004) Use of Antimicrobials in the Cattle and Development of Resistance. EMBRAPA, Campo Grande. 
[23] Erskine, R.J., Walker, R.D., Bolin, C.A., Bartlett, P.C. and White, D.G. (2002) Trends in Antibacterial Susceptibility of Mastitis Pathogens during a Seven-Year Period. Journal of Dairy Science, 85, 1111-1118. http://dx.doi.org/10.3168/jds.S0022-0302(02)74172-6

[24] Lin, G., Wu, C., Wang, X. and Meng, J. (2015) Prevalence and Characterization of Methicillin Susceptible Staphylococcus aureus ST398 Isolates from Retail Foods. International Journal of Food Microbiology, 196, 94-97. http://dx.doi.org/10.1016/j.ijfoodmicro.2014.12.002

[25] Hososaka, Y., Hanaki, H., Endo, H., Suzuki, Y., Nagasawa, Z., Otsuka, Y., Nakae, T. and Sunakawa, K. (2007) Characterization of Oxacillin-Susceptible mecA-Positive Staphylococcus aureus: A New Type of MRSA. Journal of Infection and Chemotherapy, 13, 79-86. http://dx.doi.org/10.1007/s10156-006-0502-7

[26] Shahraz, F., Dadkhah, H., Khaksar, R., Mahmoudzadeh, M., Hosseini, H. and Kamran, M. (2012) Analysis of Antibiotic Resistance Patterns and Detection of mecA Gene in Staphylococcus aureus Isolated from Packaged Hamburger. Meat Science, 90, 759-763. http://dx.doi.org/10.1016/j.meatsci.2011.11.009 